\title{
Territorial behavior in juvenile red sea bream Pagrus major and crimson sea bream Evynnis japonica
}

\author{
TAKAYA KUDOH ${ }^{\mathrm{a} *}$ AND KOSAKU YAMAOKA
}

Laboratory of Aquatic Ecology, Department of Aquaculture, Kochi University, Nankoku, Kochi 783-8502, Japan

\begin{abstract}
The territorial behavior of juvenile red sea bream Pagrus major and crimson sea bream Evynnis japonica was examined at Morode Cove, Ehime Prefecture. Four exclusive types of behavior (attack, mutual attack, head down threat and mutual display) and one escaping behavior (fleeing) were observed in both species. Juvenile of the two sea bream could discriminate between each other and change their territorial behavior depending on the presence of conspecifics or heterospecifics. The territorial behavior toward conspecifics was more aggressive than toward heterospecifics. Interrelationships between the two sea bream were more aggressive than in other heterospecific cases. The two sea breams performed following behaviors toward solo and schooled mullid species. E. japonica ascended the water column more frequently than $P$. major in high frequency. The former joined conspecific aggregations foraging for planktonic animals around their territories. These observations suggest that territorial individuals of the two sea bream could discriminate intruders utilizing similar food resources in order to maintain their territories.
\end{abstract}

KEY WORDS: juvenile, crimson sea bream, following behavior, red sea bream, territorial behavior.

\section{INTRODUCTION}

Red sea bream Pagrus major and crimson sea bream, Evynnis japonica are both economically important species from the coastal waters of Japan. Over 20 million artificial seedlings of the former species are released into natural waters annually, mainly in south-western Japan. ${ }^{1}$

In the past 10 years, ecologic characteristics of juvenile red and crimson sea bream have been studied by the members of Kochi University mainly by means of scuba diving. ${ }^{2-5}$ They clarified that both of the two species hold the territories, which plays an important role in regulating the population density in their nursery ground. The two species also have an interaction regarding territory establishment. However, there have been no studies defining the territories clearly from a quantitative point of view and describing their behavioral characteristics in detail. In order to

*Corresponding author: Tel: 81-823-51-2171.

Fax: 81-823-52-2683. Email: t-kudou86058@pref.hiroshima.jp

aPresent address: Hiroshima Prefectural Fisheries Experimental Station, Ondo, Hiroshima 737-1207, Japan.

Received 14 February 2003. Accepted 10 November 2003. develop a rational, biodiversity-oritented releasing technique for the artificial seedlings of the red sea bream, more detailed information concerning the territoriality of the two species is needed. In the present study, we aim to describe the behavioral characteristics of the territoriality of these two closely related sea bream observed in natural waters.

\section{MATERIALS AND METHODS}

Underwater observations of the types of territorial behavior of the juveniles of the two species were undertaken from March to September 1995, at a depth of approximately $4 \mathrm{~m}$ in a nursery at Morode Cove in Ehime Prefecture $\left(33^{\circ} 00^{\prime} \mathrm{N}, 132^{\circ} 30^{\prime} \mathrm{E}\right)$. We established two observation sites $(10 \mathrm{~m} \times 20 \mathrm{~m})$ in the same study area. ${ }^{3}$ Fish in each observation site could be identified by tatoo-marking (Table 1). We observed 26 territorial individuals of P. major for 820 min (Table 2) and 21 territorial individuals of E. japonica for $700 \mathrm{~min}$ (Table 3), respectively. We determined whether or not a fish was territorial by observing the reactions of a given fish towards approaching conspecifics or heterospecifics, both inside and outside a $0.5 \mathrm{~m}$ radius from the subject 
fish, and recorded the reactions displayed inside the radius as territorial behavior. When a fish did not show any reactions towards other conspecifics or heterospecifics inside the radius, we regarded it as having no reaction. Species that had encounter times with juvenile red sea bream of $<5$ were omitted from the data.

When observing the types of behavior between the two species, the size of the fish concerned was also estimated by the naked eye. In this case, a fish that was larger (smaller) than its counterpart by $>5 \mathrm{~mm}$ was considered a larger (smaller) individual. Fish with a size difference of $<5 \mathrm{~mm}$ were considered to be a similar size.

Table 1 Total body length ( $\mathrm{mm}$ ) of two sea bream species individually identified at two observation sites

\begin{tabular}{|c|c|c|}
\hline & $\begin{array}{c}P . \text { major } \\
\text { Mean } \pm \text { SD }(n)\end{array}$ & $\begin{array}{c}\text { E. japonica } \\
\text { Mean } \pm \operatorname{SD}(n)\end{array}$ \\
\hline Site 1 & $55.4 \pm 9.5$ & $61.7 \pm 10.2(48)$ \\
\hline Site 2 & $47.2 \pm 8.5(129)$ & $58.4 \pm 10.1$ \\
\hline
\end{tabular}

Tatoo marking was conducted from 26 April to 24 May.
The two species exhibited the following behavior toward fish intruding into their territories. Following behavior was defined as a territorial fish swimming $>0.1 \mathrm{~m}$ just above the sea bottom following the intruding fish inside a $0.5 \mathrm{~m}$ radius. We recorded the number of individuals of each species that were followed.

In order to compare behavioral characteristics between the two species in their territories, we also observed how many times a fish ascended in a water column situated $>0.5 \mathrm{~m}$ above the bottom per 10 min (ascending behavior).

\section{RESULTS}

\section{Variety of territorial behavior}

Juveniles of both species showed territorial behavior toward conspecifics or some other species that came near or might invade their territory (figures of territorial behavior are given in Kudoh and Yamaoka, and Kudoh et al. ${ }^{3,5}$ ). The territorial behavior observed in the two species consisted of

Table 2 No. encounters in individually identified P. major toward fish in three groupings

\begin{tabular}{|c|c|c|c|c|}
\hline \multirow[b]{2}{*}{ Individuals } & \multirow[b]{2}{*}{$n$} & \multicolumn{3}{|c|}{ No. encounters } \\
\hline & & Conspecifics & E. japonica & Heterospecifics $^{\dagger}$ \\
\hline$P m 1$ & 4 & 16 & 26 & 0 \\
\hline$P m 2$ & 2 & 7 & 0 & 2 \\
\hline Pm3 & 1 & 0 & 0 & 0 \\
\hline $\mathrm{Pm} 4$ & 1 & 1 & 1 & 0 \\
\hline Pm5 & 4 & 9 & 27 & 4 \\
\hline Pm6 & 3 & 11 & 1 & 12 \\
\hline$P m 7$ & 6 & 16 & 0 & 16 \\
\hline Pm8 & 3 & 7 & 4 & 16 \\
\hline$P m 9$ & 1 & 1 & 0 & 0 \\
\hline Pm 10 & 3 & 12 & 0 & 10 \\
\hline$P m 11$ & 1 & 0 & 11 & 5 \\
\hline Pm12 & 3 & 3 & 10 & 5 \\
\hline$P m 13$ & 4 & 8 & 10 & 4 \\
\hline Pm14 & 8 & 32 & 25 & 10 \\
\hline Pm15 & 4 & 1 & 38 & 0 \\
\hline$P m 16$ & 1 & 2 & 0 & 0 \\
\hline Pm17 & 3 & 13 & 12 & 2 \\
\hline Pm18 & 2 & 2 & 3 & 0 \\
\hline Pm19 & 2 & 2 & 22 & 0 \\
\hline Pm 20 & 1 & 2 & 0 & 0 \\
\hline$P m 21$ & 5 & 8 & 8 & 4 \\
\hline$P m 22$ & 4 & 9 & 3 & 30 \\
\hline Pm 23 & 5 & 1 & 18 & 8 \\
\hline Pm24 & 5 & 20 & 0 & 32 \\
\hline Pm25 & 1 & 5 & 4 & 0 \\
\hline$P m 26$ & 5 & 10 & 5 & 14 \\
\hline Total & 82 & 198 & 228 & 174 \\
\hline
\end{tabular}

${ }^{\dagger}$ Heterospecific fish except for E. japonica.

Pm, P. major. 
five types that were common to both species, and another that was specific to the crimson sea bream. In the territorial behavior of (1-4) juveniles of both species extended their fins.

(1) Attack: strong aggressive behavior displayed by a territory holder to invaders who are driven away one-sidedly.

(2) Mutual attack: mutual fight between a territory holder and neighboring invader inside or near the boundary of the territories. In this case, both fish attack each other toward the mouth, head and belly regions, and then they return to a certain position in their own territories. At the end of these attacks, territorial fish perform a mutual display. At that time, P. major sometimes bit each other's mouth.

(3) Head down threat: a display shown by a territory holder to neighboring invaders near the boundary. The territory holder threatens the invaders by slightly dipping its head.

(4) Mutual display: a mutual display performed by both territory holder and its neighbor near the boundary. The two fish recede slowly, displaying.

(5) Fleeing: an escape behavior displayed by a territory holder from a one-sided attack by a neighboring fish. The territory holder temporarily flees back to its own territory and the interaction between them finishes, sometimes after display of some territorial behavior.

(6) Mouth-to-mouth display: a mutual display performed by two territory holders around the boundary. The two fish open their mouth widely and press them against each other, acccompanied by up-and-down movements from just above the sea bottom to $10 \mathrm{~cm}$ above it. This behavior was observed only in E. japonica.

In many cases of territorial interaction, fish body color changed. In P. major, the color from the head to the dorsal part changed to a dark brown and the general body color became more yellowish. In some cases, dark brown vertical bands appeared on the side of the body. In E. japonica, the color from the head to the dorsal part changed into a strong red-purple, but the vertical bands did not appear. In the present paper, we treat exclusive behaviors, in all encounters, as except fleeing and no interaction.

\section{Territorial behavior of red sea bream}

Juvenile red sea bream had 176 interactions out of 198 encounters with conspecifics (Table 4). The total interactions consisted of 10 occurrences of fleeing and 166 occurrences of exclusive behavior $(88.3 \% ; 166 / 188)$. No interaction occurred in 22 of the encounters $(11.7 \% ; 22 / 188)$. The frequency of
Table 3 No. encounters in individually identified $E$. japonica toward fish in three groupings

\begin{tabular}{|c|c|c|c|c|}
\hline \multirow[b]{2}{*}{ Individuals } & \multirow[b]{2}{*}{$n$} & \multicolumn{3}{|c|}{ No. encounters } \\
\hline & & Conspecifics & P. major & Heterospecifics $^{\dagger}$ \\
\hline$E j 1$ & 2 & 8 & 2 & 2 \\
\hline Ej2 & 2 & 11 & 9 & 2 \\
\hline$E j 3$ & 14 & 12 & 0 & 14 \\
\hline Ej4 & 1 & 1 & 11 & 1 \\
\hline Ej5 & 2 & 11 & 1 & 0 \\
\hline Ej6 & 4 & 37 & 9 & 2 \\
\hline Ej7 & 14 & 37 & 0 & 29 \\
\hline Ej8 & 1 & 4 & 1 & 0 \\
\hline Ej9 & 1 & 4 & 1 & 4 \\
\hline Ej10 & 1 & 0 & 0 & 0 \\
\hline Ej11 & 3 & 6 & 3 & 5 \\
\hline Ej12 & 3 & 17 & 2 & 4 \\
\hline Ej13 & 2 & 1 & 0 & 3 \\
\hline Ej14 & 6 & 36 & 4 & 6 \\
\hline Ej15 & 1 & 2 & 1 & 1 \\
\hline Ej16 & 2 & 8 & 1 & 1 \\
\hline Ej17 & 2 & 2 & 10 & 5 \\
\hline Ej18 & 4 & 22 & 5 & 1 \\
\hline Ej19 & 2 & 8 & 7 & 0 \\
\hline Ej20 & 1 & 4 & 3 & 0 \\
\hline Ej21 & 2 & 10 & 0 & 2 \\
\hline Total & 70 & 241 & 70 & 82 \\
\hline
\end{tabular}

${ }^{\dagger}$ Heterospecific fish except for P. major.

Ej, E. japonica.

Table 4 Intraspecific territorial behavior of red sea bream

\begin{tabular}{lrrrr}
\hline & \multicolumn{3}{c}{ Relative size of intruders } & \\
\cline { 2 - 4 } Response of owners & Larger & Similar & Smaller & Total \\
\cline { 2 - 4 } Attack & 21 & 18 & 33 & 72 \\
Mutual attack & 3 & 2 & 2 & 7 \\
Head-down threat & 18 & 17 & 5 & 40 \\
Mutual display & 13 & 5 & 29 & 47 \\
Fleeing & 6 & 1 & 3 & 10 \\
No interaction & 13 & 1 & 8 & 22 \\
Total & 74 & 44 & 80 & 198 \\
& & & & \\
\hline
\end{tabular}

the display of exclusive behavior differed among the three relative size differences (similar, 95.5\%; smaller, $86.3 \%$; larger, $74.3 \%$ ) of the two fish concerned $\left(\chi^{2}\right.$ test, $\chi_{\text {cal }}{ }^{2}=7.6$, d.f. $\left.=2, P<0.05\right)$.

Juvenile red sea bream had 106 interactions out of 228 encounters with intruding juvenile crimson sea bream (Table 5). The total interactions consisted of 20 occurrences of fleeing and 86 occurrences of exclusive behavior $(41.3 \%$; $86 / 208)$. No interaction occurred in 122 of the encounters $(58.7 \% ; 122 / 208)$. The frequency of the display of exclusive behavior did not differ among the three relative size differences (similar, 46.2\%; larger, $40.3 \%$; smaller, $31.1 \%$ ) of the two fish concerned 
$\left(\chi^{2}\right.$ test, $\chi_{\text {cal }}^{2}=4.7$, d.f. $\left.=2, P>0.05\right)$. However, the frequency of exclusive behavior of red sea bream towards conspecifics $(88.3 \%)$ was higher than that of crimson sea bream $\left(41.3 \%\right.$; $\chi^{2}$ test, $\chi_{\text {cal }}{ }^{2}=94.1$, d.f. $=1, P<0.0001)$.

Many fish species, that is, gerreid Gerres oyena, monacanthid Stephanolepis cirrhifer, callionymid Repomucenus richardsonii, four mullid species Upeneus tragula, U.japonicus, Parupeneus chrysopleuron and P. heptacanthus shared the habitats of the territorial juveniles of red sea bream. Juvenile red sea bream had 36 interactions out of 174 encounters with those fish species (Table 6). The total interactions consisted of two occurrences of fleeing, 20 occurrences of exclusive behavior (12.7\%; 20/158) and 14 occurrences of following. No interaction occurred in 138 of their encounters $(87.3 \% ; 138 / 158)$. The following behavior was observed only toward members of the mullid fishes (U. tragula, P. heptacanthus, P. chrysopleuron, and U. japonicus). Red sea bream usually foraged during following except for U.japonicus. The frequency of occurrence of exclusive behavior of red sea bream toward other fish $(12.7 \%)$ was lower than that of crimson sea bream $\left(41.3 \%\right.$; $\chi^{2}$ test, $\chi_{\text {cal }}{ }^{2}=35.9$, d.f. $=1, P<0.0001$ ).

We observed the interrelationships between the red sea bream and other fish species that invaded their territories in schools. The mullids (P.

Table 5 Territorial behavior of red sea bream toward crimson sea bream

\begin{tabular}{lcccr}
\hline & \multicolumn{3}{c}{ Relative size of intruders } & \\
\cline { 2 - 4 } Response of owners & Larger & Similar & Smaller & Total \\
\hline Attack & 18 & 6 & 16 & 40 \\
Head-down threat & 15 & 2 & 7 & 24 \\
Mutual display & 15 & 4 & 3 & 22 \\
Fleeing & 18 & 0 & 2 & 20 \\
No interaction & 53 & 14 & 55 & 122 \\
Total & 119 & 26 & 83 & 228 \\
& & & & \\
\hline
\end{tabular}

chrysopleuron, P. heptacanthus, Parupeneus spilurus, Parupeneus barberinus and U. tragula) were included in every school, and the number of all individuals of the school including other fish (labrid Pseudolabrus sp., lethrinid Lethrinus genivittatus and monacanthid S. cirrhifer) were from 2 to 8 . The schools were divided into a monospecific school of mullid species, a multispecific school of mullids and a school including nonmullid species. In 15 observations, juvenile red sea bream displayed a high frequency of the following behavior toward a school including P. chrysopleuron (11 times; 3.1 individuals \pm 2.2 ; mean $\pm \mathrm{SD}$ ), and that including P. heptacanthus (nine times; 2.3 individuals \pm 2.0 ), compared with a school including other mullid species or nonmullid species (1-3 times). Red sea bream followed one school for $54-377 \mathrm{~s} \quad(143 \pm 98.5 \mathrm{~s}$; mean $\pm \mathrm{SD}$ ). Foraging behavior was always observed during the following behavior (4.4 \pm 1.9 times/min; range: $1.1-6.9$ times $/ \mathrm{min}$ ).

\section{Territorial behavior of crimson sea bream}

Juvenile crimson sea bream had 201 interactions out of 241 encounters with conspecifics (Table 7). The total interactions consisted of 29 occurrences of fleeing and 172 occurrences of exclusive behavior (81.1\%; 172/212). No interaction occurred in 40 of their encounters $(18.9 \%$; $40 /$ 212). The frequency of the display of exclusive behavior did not differ among the three relative size differences (similar, 79.6\%; smaller, $75.4 \%$; larger, $58.6 \%)$ of the two fish concerned $\left(\chi^{2}\right.$ test, $\chi_{\text {cal }}{ }^{2}=3.2$, d.f. $=2, P>0.05$ ).

Juvenile crimson sea bream had 40 interactions out of 70 encounters with intruding juvenile red sea bream (57.1\%; Table 8$)$.

The total interactions consisted of 16 occurrences of fleeing and 24 occurrences of exclusive behavior $(44.4 \%$; $24 / 54)$. No interaction occurred

Table 6 Territorial behavior of red sea bream toward fish species other than the red or crimson sea bream

\begin{tabular}{|c|c|c|c|c|c|c|c|c|}
\hline \multirow{2}{*}{$\begin{array}{l}\text { Response of } \\
\text { owners }\end{array}$} & \multicolumn{7}{|c|}{ Species } & \multirow[b]{2}{*}{ Total } \\
\hline & G. oyena & S. cirrhifer & R. rechardsonii & U. tragula & U. japonicus & P. chrysopleuron & P. heptacanthus & \\
\hline Attack & 6 & 1 & 7 & 0 & 1 & 2 & 0 & 17 \\
\hline Head-down threat & 0 & 0 & 0 & 0 & 0 & 1 & 2 & 3 \\
\hline Following & 0 & 0 & 0 & 7 & 1 & 4 & 2 & 14 \\
\hline Fleeing & 0 & 2 & 0 & 0 & 0 & 0 & 0 & 2 \\
\hline No interaction & 47 & 46 & 3 & 9 & 20 & 12 & 1 & 138 \\
\hline Total & 53 & 49 & 10 & 16 & 22 & 19 & 5 & 174 \\
\hline
\end{tabular}

G. oyena, Gerres oyena; S. cirrhifer, Stephanolepis cirrhifer; R. rechardsonii, Repomucenus rechardsonii; U. tragula, Upeneus tragula; U. japonicus, Upeneus japonicus; P. chrysopleuron, Parupeneus chrysopleuron; P. heptacanthus, Parupeneus heptacanthus. 
in 30 of their encounters $(55.6 \%$; 30/54). The frequency of the display of exclusive behavior did not differ between the two relative size differences (larger and similar, $61.1 \%$; smaller, $50.0 \%$ ) of the two fish concerned $\left(\chi^{2}\right.$ test, $\chi_{\text {cal }}^{2}=3.0$, d.f. $=1$, $P>0.05)$. However, the frequency of exclusive behavior of crimson sea bream toward conspecifics $(81.1 \%)$ was higher than that of red sea bream (44.4\%; $\chi^{2}$ test, $\chi_{\text {cal }}{ }^{2}=29.9$, d.f. $\left.=1, \mathrm{P}<0.0001\right)$.

Gerres oyena, S. cirrhifer, U. japonicus and the pinguipedid Parapercis pulchella shared the habitat with territorial juveniles of the crimson sea bream. Juvenile crimson sea bream had nine interactions out of 82 encounters with those fish species (Table 9). The total interactions consisted of five occurrences of fleeing, three occurrences of exclusive behavior $(3.9 \% ; 3 / 76)$ and one occurrence of

Table 7 Intraspecific territorial behavior of crimson sea bream

\begin{tabular}{lrrrr}
\hline & \multicolumn{3}{c}{ Relative size of intruders } \\
\cline { 2 - 4 } Response of owners & Larger & Similar & Smaller & Total \\
\hline Attack & 11 & 21 & 60 & 92 \\
Mutual attack & 2 & 0 & 0 & 2 \\
Head-down threat & 4 & 4 & 10 & 18 \\
Mutual display & 11 & 10 & 16 & 37 \\
Month to month display & 13 & 4 & 6 & 23 \\
Fleeing & 15 & 5 & 9 & 29 \\
No interaction & 14 & 5 & 21 & 40 \\
Total & 70 & 49 & 122 & 241 \\
& & & &
\end{tabular}

Table 8 Territorial behavior of crimson sea bream toward red sea bream

\begin{tabular}{lccr}
\hline & \multicolumn{2}{c}{ Relative size of intruders } & \\
\cline { 2 - 3 } Response of owners & Larger and similar & Smaller & Total \\
\hline Attack & 5 & 5 & 10 \\
Head-down threat & 5 & 3 & 8 \\
Mutual display & 1 & 5 & 6 \\
Fleeing & 6 & 10 & 16 \\
No interaction & 7 & 23 & 30 \\
Total & 24 & 46 & 70 \\
\hline
\end{tabular}

following. No interaction occurred in 73 of their encounters $(96.1 \% ; 73 / 76)$. The frequency of exclusive behavior of crimson sea bream toward other fish $(3.9 \%)$ was lower than that of red sea bream (44.4\%; $\chi^{2}$ test, $\chi_{\text {cal }}{ }^{2}=31.5$, d.f. $\left.=1, P<0.0001\right)$.

\section{Ascending behavior}

Juvenile crimson sea bream ascended to $>0.5 \mathrm{~m}$ in the water column from the bottom more frequently $(1.7 \pm 2.2$ times $/ 10 \mathrm{~min})$ than did juvenile red sea bream $(0.1 \pm 0.4$ times/10 min; MannWhitney $U$-test, $\left.U_{\text {cal }}=1430.5, P<0.001\right)$. When the rate of the number of fish with ascending behavior was compared to the total number of fish observed in each species, the crimson sea bream displayed this more frequently (43.5\%) than did red sea bream $\left(11.3 \%\right.$; $\chi^{2}$ test, $\chi_{\text {cal }}{ }^{2}=31.9$, d.f. $\left.=1, P<0.001\right)$.

Juvenile crimson sea bream joined conspecific aggregations displaying foraging behavior in the water column in 12 out of 38 times during ascending behavior (31.6\%). This behavior was observed only in crimson sea bream.

\section{DISCUSSION}

Juveniles of the two sea bream altered their defense tactics according to the fish species that invaded their territories. Fish of the same species were most strongly excluded. The exclusive behavior toward other species was not so strong as that between conspecifics. However, interrelationships between the two sea bream were more aggressive than in other heterospecific cases. ${ }^{3,5}$ Eupomacentrus altus, an algal feeding damsel fish, also changed its territorial behavior depending on fish species and feeding habits, and formed a three-hold territory. ${ }^{6}$ Although the two species observed in the present study did not show such clear difference in territorial behaviors toward various invaders as that of E. altus, it is clear that the two species can recognize the species of invaders. Here, species recognition means that the territory holder can make

Table 9 Territorial behavior of crimson sea bream toward fish species other than the red or crimson sea bream

\begin{tabular}{|c|c|c|c|c|c|}
\hline \multirow[b]{2}{*}{ Response of owners } & \multicolumn{4}{|c|}{ Species } & \multirow[b]{2}{*}{ Total } \\
\hline & G. oyena & S. cirrhifer & P. pulchella & U. japonicus & \\
\hline Attack & 1 & 0 & 0 & 1 & 2 \\
\hline Head-down threat & 1 & 0 & 0 & 0 & 1 \\
\hline Following & 1 & 0 & 0 & 0 & 1 \\
\hline Fleeing & 0 & 2 & 3 & 0 & 5 \\
\hline No interaction & 38 & 18 & 8 & 9 & 73 \\
\hline Total & 41 & 20 & 11 & 10 & 82 \\
\hline
\end{tabular}

P. pulchella, Parapercis pulchella. Remainder of species names as per Table 6. 
judgments regarding the interest they have in the invaders.

Other evidence supporting the red sea bream's ability to recognize other species lies in the fact that the juveniles displayed following behavior toward mullid fish and S. cirrhifer ${ }^{5}$ The following behavior has been frequently studied for many fish species and some species of the mullid fish have been reported to be the nuclear species..$^{7-12}$ Fishelson observed that G. oyena and labrid fishes gathered in the sandy dust that was stirred up by the mullid fish's foraging behavior, in which it thrusts its head into the sea bottom. ${ }^{8}$ The same head thrust behavior in foraging was observed in $P$. heptacanthus and P.chrysopleuron (Kudoh T, unpubl. data, 1999).

The data suggested that the fish species followed by red sea bream whose primary food is epifaunastic animals, ${ }^{13}$ give the red sea bream chances to take usually inaccessible benthic animals (e.g. deep burrower type of gammarid species) that have been temporarily exposed.

When the defended area was formed around the areas where the crab Thalamita sima ${ }^{2}$ and S. cirrhifer $^{5}$ stirred the sandy bottom, similar environmental conditions seem to be formed by foraging mullid fishes (e.g. P. heptacanthus and P. chrysopleuron).

The frequency of ascending behavior of juvenile crimson sea bream in their territory was much higher than that of red sea bream. In addition, crimson sea bream joined conspecific schools or aggregations displaying foraging behavior during their ascending behavior. The frequency of the foraging behavior (water column feeding) of the crimson sea bream was higher than that of red sea bream. ${ }^{4}$ These behavioral differences between the two species suggest that crimson sea bream can widely utilize not only benthic animals but also planktonic animals around the territories. This is supported by the fact that the solitary (territorial) crimson sea bream $50-80 \mathrm{~mm}$ in fork length utilized some planctonic animals (e.g. Copepoda, 19.1-75.8\%; Appendicularia, $2.7-24.9 \%$ by the numerical method). ${ }^{14}$ Accordingly, food resource partitions derived from the behavioral difference between the two species might reduce the frequency of exclusive behavior toward the heterospecific fish, which would facilitate the coexistence of the two closely related spared species in the nursery ground.

\section{ACKNOWLEDGMENTS}

We thank DrYYanagisawa of the Faculty of Science, Ehime University, for giving us permission to use the facilities of the UWA Station (a private station for students of Ehime University). Thanks are also due to the members of the station for their support. The present study was financially supported in part by the Ministry of Agriculture, Forestry, and Fisheries, Japan.

\section{REFERENCES}

1. Anonymous. General situation of aquacultual undertakings in recent year. Fisheries Agency of Japan and Japan Sea Farming Association, Tokyo. 2001.

2. Yamaoka K, Takagi M, Yamada T, Taniguchi N. Territorial behaviour of released juvenile red sea bream. Nippon Suisan Gakkaishi 1991; 57: 1-5.

3. Kudoh T, Yamaoka K. Territorial behaviour of juvenile crimson sea bream Evynnis japonica at Murote Cove in Ehime Prefecture. Nippon Suisan Gakkaishi 1995; 61: 499504.

4. Kudoh T, Yamaoka K. Territory established location and foraging behaviour of juveniles of red sea bream Pagrus major and crimson sea bream Evynnis japonica. Nippon Suisan Gakkaishi 1998; 64: 16-25.

5. Kudoh T, Suetomo K, Yamaoka K. Distribution and behaviour of wild and artificially reared red sea bream Pagrus major at Morode Cove in Ehime Prefecture. Nippon Suisan Gakkaishi 1999; 65: 230-240.

6. Kohda M. Intra- and interspecific territoriality of a temperate damselfish, Eupomacentrus altus (Teleostei, Pomacentridae). Physiol. Ecol. Jpn 1984; 21: 35-52.

7. Montgomery WL. Interspecific associations of sea basses (Serranidae) in the Gulf of California. Copeia 1975; 1975; 785-787.

8. Fishelson L. Sociobiology of feeding behaviour of coral fish along the coral reef of the gulf of Eliot (=Gulf of Aqaba), Red Sea. Isr. J. Zool. 1977; 26: 114-134.

9. Ormond RFG. Aggressive mimicry and other interspecific feeding associations among Red Sea coral reef predators. $J$. Zool. Lond. 1980; 191: 247-262.

10. Diamant A, Shpigel M. Interspecific feeding associations of groupers (Teleostei. Serridae) with octopuses and moray eels in the Gulf of Eliat (Aqaba). Environ. Biol. Fish. 1985; 13: $153-159$.

11. Strand S. Following behaviour: interspecific foraging associations among Gulf of California reef fishes. Copeia 1988; 1988; 351-357.

12. Sakai Y, Kohda M. Foraging by mixed-species groups involving a small angel fish, Centropyge ferrugatus (Pomacanthidae). Jpn. J. Ichthyol. 1995; 41: 429-435.

13. Sudo H, Azuma M, Azeta M. Diel changes in predator-prey relationships between red sea bream and gammaridean amphipods in Shijiki Bay. Nippon Suisan Gakkaishi 1987; 53: 1567-1575.

14. Yamaoka K, Sasaki M, Kudoh T, Kanda M. Difference in food composition between territorial and aggregative juveniles of the crimson sea bream Evynnis japonica. Fish. Sci. 2003; 69: 50-57. 